\title{
Multiple emulsions containing amazon oil: açaí oil (Euterpe oleracea)
}

\author{
Márcio Ferrari, ${ }^{*}, 1,2,3$ Pedro Alves da Rocha-Filho ${ }^{3}$ \\ ${ }^{1}$ Departamento Farmacêutico, Universidade de Cuiabá, Brazil, \\ ${ }^{2}$ Departamento de Farmácia, Universidade Federal do Rio Grande do Norte \\ Brazil, \\ ${ }^{3}$ Departamento de Ciências Farmacêuticas, Universidade de São Paulo, \\ Brazil.
}

\begin{abstract}
The aim of this work was to formulate $\mathrm{O} / \mathrm{W} / \mathrm{O}$ multiple emulsions containing açaí oil as a model system and to evaluate their physical stability and in vivo Sun Protection Factor (SPF). Multiple emulsions are complex dispersion systems, known also as, "emulsions of emulsions". These emulsion systems, have significant potential in the cosmetic industry. Euterpe oleracea Mart., Arecaceae, popularly known in Brazil as "açaí", is an economically important plant. Açaí oil has been used as antioxidant and as anti-inflammatory activities. The multiple emulsions were prepared using a two-step procedure. The investigated formulations were characterized and their stability over time was evaluated by preliminary and accelerated stability. $\mathrm{O} / \mathrm{W} / \mathrm{O}$ multiple emulsions containing the same concentration of sunscreens with and without açaí oil were evaluated by the International Sun Protection Factor Test Method. The samples containing 70\% (w/w) of primary emulsion, 5\% (w/w) PEG-30-dipolyhydroxystearate, 10\% (w/w) of açaí oil and $5 \%(\mathrm{w} / \mathrm{w})$ of sucrose polybehenate have been found to be stable. The rheological measurements revealed that the samples exhibited non-Newtonian pseudoplastic flow behavior and thixotropy. To conclude, no statistical difference could be observed on the in vivo SPF to both multiple systems with or without açaí oil.
\end{abstract}

Revista Brasileira de Farmacognosia

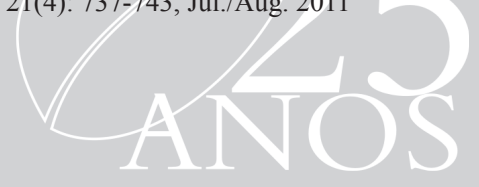

\section{Article}

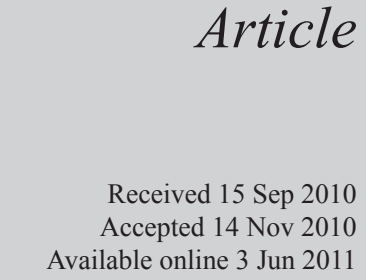

Keywords:

açaí

Euterpe oleracea

in vivo sun protection factor multiple emulsions

ISSN 0102-695X

doi: 10.1590/S0102-695X2011005000093

\section{Introduction}

The multiple emulsions present many interesting potential applications in the cosmetic, pharmaceutical, food and agricultural industries (Tedajo et al., 2005; Bonnet et al., 2009; Elshafei et al., 2010; Lima et al., 2010). They are also known as "emulsions of emulsions" (Becher, 1965; Florence \& Whitehill, 1982) since they are systems in which both types of emulsions (W/O and $\mathrm{O} / \mathrm{W}$, or $\mathrm{O} / \mathrm{W}$ and $\mathrm{W} / \mathrm{O}$ ) exist simultaneously (Omotosho, 1990), and they can be either $\mathrm{W} / \mathrm{O} / \mathrm{W}$ or O/W/O (Erös et al., 1990).

They can encapsulate substances in different phases, protect them, modulate their release rate and even possibly combine incompatible substances within their phases (Nakhare \& Vyas, 1996; Vasiljevic et al., 2006). However, despite their potential, the application of multiple emulsions has been limited by their inherent thermodynamic instability (Florence \& Whitehill, 1981; 1982; Geiger et al., 1998).

The stability of the emulsions is affected by several factors such as the composition, size of the globules, viscosity, volume of phases, $\mathrm{pH}$, presence of electrolytes, osmotic gradient and the properties of the interfacial film formed (Baillet et al., 1994; Gallardo et al., 1999; Özer et al., 2000; Rajinder, 2008; Schmidts et al., 2009). The majority of studies about multiple emulsions are confined to the $\mathrm{W} / \mathrm{O} / \mathrm{W}$ type. Even though $\mathrm{O} / \mathrm{W} / \mathrm{O}$ emulsions are expected to be used in the controlled release and stabilization of lipophilic actives, research on them is limited because of the practical difficulty in preparing a stable outer $\mathrm{W} / \mathrm{O}$ emulsion (Yoshida et al., 1999).

Exposure to solar radiation has a variety of harmful effects on human health. Some of these effects include the induction of photosensitization, immunosuppression, photocarcinogenesis and photoaging (Schauder \& Ippen, 1997; Kullavanijaya \& Lim, 2005). However, the ultraviolet (UV) dose absorbed by the skin can be reduced by limiting exposure to the sun, by wearing protective clothing and through the use of photoprotective agents such as sunscreens (van der Pols et al., 2006; Ghazi et al., 2010).

Due to the benefits of products containing natural compounds and the recent desire of the consumers for these products, the use of natural compounds that can absorb UV radiation is of great interest. Previous studies have presented evidence for 
the ability of extracts and vegetable oils to provide UV absorption or photoprotection (Katiyar \& Elmets, 2001; Moquio et al., 2005; Souza et al. 2005; Ferrari et al., 2007; 2008; Velasco et al., 2008; Violante et al., 2008; Violante et al., 2009).

Euterpe oleracea Mart., Arecaceae, locally known in Brazil as "açaí" is a slender, multistemed, monoecious palm distributed in the Amazon estuary floodplains (Muñiz-Miret et al., 1996). Due to its high consumption and commercialization, açaí had long been restricted to a regional level in Brazil; however, increased international and expanded distribution has made the açaí, and various products made from açaí, widely available to the general public (Pacheco-Palencia et al., 2007).

Considerable interest has been generated by the açai's high antioxidant capacity, attributed to its polyphenolic compounds (Lichtenthãler et al., 2005; Pacheco-Palencia et al., 2007; Kang et al., 2010). Anthocyanins are the predominant polyphenols and account for more than $90 \%$ of açaí's total polyphenolic contents (Pacheco-Palencia et al., 2009). Other nonanthocyanin polyphenol and phenolic acids were also present (Gallori et al., 2004; Lichtenthãler et al., 2005; Pacheco-Palencia et al., 2009; Tonon et al., 2010). On the other hand, anthocyanins, which belong to one class of polyphenols, may serve as antioxidants and play a photoprotective role by directly eliminating the reactive oxygen species during photooxidative stress (Zhang et al., 2010).

The anti-inflammatory activity caused by the inhibitory effects on nitric oxide (NO) production by activated macrophage cell was reported by Matheus et al., (2006). The oral contrast agent used in magnetic resonance imaging and the vasodilator effect have been reported (Córdova-Fraga et al., 2004; Rocha et al., 2007). Ribeiro et al. (2010) also observed that açaí pulp was not genotoxic in mouse bone marrow or liver and kidney cells and plays a role in inhibiting the genotoxicity induced by the antitumoral agent DXR.

The aim of this work was to formulate $\mathrm{O} / \mathrm{W} / \mathrm{O}$ multiple emulsions containing açaí oil as a model system and to evaluate their physical stability and in vivo Sun Protection Factor (SPF).

\section{Materials and Methods}

\section{Materials}

Acrylates/C10-30 alkyl acrylate crosspolymer and carbomer (BFGoodrich, Dinaco SA, São Paulo, Brazil), caprylic/ capric triglyceride, oleyl alcohol, sucrose polybehenate, and ethylhexyl stearate were gifts from Croda do Brasil Ltda (Campinas, Brazil), BHT, EDTA, and triethanolamine were purchased from Henrifarma Ltda (São Paulo, Brazil), octocrylene, 2-ethylexyl salicylate, 2-ethylhexyl 4- methoxycynnamate and phenoxyethanol and caprylyl glycol were gifts from ISP Corp. (São Paulo, Brazil), bis-ethylhexyloxyphenol methoxyphenyl triazine were gifts from Ciba Specialty Chemicals Inc. (São Paulo, Brazil), mineral oil and propylene glycol were acquired from Volp Ltda (São Paulo, Brazil), PEG30 dipolyhydroxystearate and Euterpe oleracea fruit oil were gifts from Beraca Ingredients Co. (São Paulo, Brazil), and distilled water.

\section{Method of preparation and formulations}

Multiple emulsions were prepared using a two-step procedure (Florence \& Whitehill, 1982). In the first step, the $\mathrm{O} / \mathrm{W}$ emulsion (F1) was prepared by heating the oil phase to $50 \pm 2{ }^{\circ} \mathrm{C}$ and then adding it to the aqueous phase (Table 1), followed by agitation for 15 min at $600 \mathrm{rpm}$ (mechanic mixer Fisaton Mod.713D). An $\mathrm{O} / \mathrm{W}$ emulsion (F2) without açaí oil was also prepared (Table 1). In the second step, the $\mathrm{O} / \mathrm{W}$ emulsion (primary emulsion) was added into the oil phase, heated to $70 \pm 2$ ${ }^{\circ} \mathrm{C}$ (Table 2), while the system was stirred at $500 \mathrm{rpm}$. After the complete introduction of the primary emulsion, stirring was maintained for $15 \mathrm{~min}$.

\section{Evaluation techniques}

The appearance, homogeneity and organoleptic characteristics were evaluated by macroscopic analyses over a course of ninety days (Ferrari et al., 2008).

Microscopic analyses (Olympus BX50, Olympus Optical Co., Ltd, Tokyo, Japan) of investigated samples were conducted to check information about the properties and multiple character of the multiple emulsions after carefully diluting samples with liquid paraffin (Ferrari et al., 2008).

\section{Stability studies}

The physical stability of the multiple emulsions was evaluated by preliminary and accelerated stability tests (Lima et al., 2008; Lima et al., 2010). The centrifugation and determination of percent phase separation were used to investigate the preliminary stability.

The centrifugation test (Fanen, mod. Excelsa Baby II, São Paulo, Brazil) was performed on freshly prepared and $24 \mathrm{~h}$ old multiple systems at $3000 \mathrm{rpm}$ for $30 \mathrm{~min}$. The percent phase separation was calculated using the equation according to Nakhare \& Vyas, (1996). These tests were carried out at $25{ }^{\circ} \mathrm{C}$.

To evaluate the accelerated stability, the samples were stored at different conditions: $4 \pm 2{ }^{\circ} \mathrm{C}$, $25 \pm 2{ }^{\circ} \mathrm{C}$ and $37 \pm 2{ }^{\circ} \mathrm{C}$ and $45 \pm 2{ }^{\circ} \mathrm{C}$ either $75 \pm 5 \%$ relative humidity $(\mathrm{RH})$. All samples were evaluated using 
macroscopic and microscopic analyses and rheological behavior $24 \mathrm{~h}$ after preparation as well as after thirty, sixty and ninety days of storage (Lima et al., 2008).

Physical stability was assessed through rheological determinations that were obtained using a model DV-III Brookfield rotational rheometer (Stoughton, MA, USA) with a cone-plate configuration and connected to a Brookfield software program (Rheocalc version v3.0). Rheological parameters were determined at $25 \pm 2{ }^{\circ} \mathrm{C}$ using a CP 52 spindle $\left(\mathrm{d}=12 \mathrm{~mm}, \theta=3.0^{\circ}\right)$ and $0.5 \mathrm{~g}$ of each sample. Rheogram curves constructed with ascendant and descendant segments were obtained with rotation speeds increasing progressively (1-50 rpm) as well as gradually decreasing (50-1 rpm). The measurements were made in intervals of $10 \mathrm{rpm}$, remaining at each speed of rotation for for $10 \mathrm{~s}$. With the obtained values from our results the consistency index, flow index and hysteresis area were calculated. Three batches were prepared, and the results were obtained with three evaluations (Lima, et al., 2008).

Statistical analyses of accelerated stability data were performed using the univariate analysis of variance and the post hoc test was examined by using Tamhane's test $(p<0.05)$ (Lima et al., 2008).

\section{In vivo sun protection factor determination}

$\mathrm{O} / \mathrm{W}$ and $\mathrm{O} / \mathrm{W} / \mathrm{O}$ emulsions containing the same concentration of sunscreens with or without açaí oil were evaluated. The in vivo SPF was determined according to the International Sun Protection Factor Test Method (Colipa et al., 2006). The CTFA/JCIA standard formulation was used to standardize this procedure. The protocol of research was approved by the Human Experimentation Committee from the University of Cuiabá, under the protocol \#0307-171. Wilcoxon no parametric tests were used to determine statistical significance $(p<0.05)$.

\section{Results and Discussion}

\section{Characteristics of multiple emulsions}

A stable primary emulsion is essential for the overall stability of multiple emulsions ( $\mathrm{Su}$ et al., 2006). The stable O/W primary emulsion, standardized by Ferrari (unpublished results) (Table 1) was used to formulate the $\mathrm{O} / \mathrm{W} / \mathrm{O}$ multiple emulsions, containing in the external oil phase: lipophilic surfactant, açaí oil, mineral oil, sunscreens and the additive for their stabilization (Table 2).

Macroscopically, the $\mathrm{O} / \mathrm{W} / \mathrm{O}$ multiple emulsions showed white and homogenous creams.

When diluted with liquid paraffin, homogenous mixtures were obtained and it was observed that the external phase was oily. Microscopic analysis was performed to show the multiplicity of multiple emulsions. The multiplicity was also was checked microscopically during the different steps of experiments.

Table 1. O/W primary emulsions composition.

\begin{tabular}{lcc}
\hline \multicolumn{1}{c}{ Components } & $\begin{array}{c}\text { Formulation 1 } \\
(\mathrm{F} 1)(\mathrm{g} \%)\end{array}$ & $\begin{array}{c}\text { Formulation 2 } \\
(\mathrm{F} 2)(\mathrm{g} \%)\end{array}$ \\
\hline Propylene glycol & 3.00 & 3.00 \\
Dissodium EDTA & 0.10 & 0.10 \\
Triethanolamine (sol. 50\%) & 0.60 & 0.60 \\
BHT & 0.10 & 0.10 \\
Euterpe oleracea fruit oil & 10.00 & ---- \\
Octocrylene & 6.00 & 6.00 \\
2- Ethylexyl salicylate & 5.00 & 5.00 \\
2-Ethylhexyl 4- methoxycynnamate & 7.50 & 7.50 \\
Bis-Ethylhexyloxyphenol & 5.00 & 5.00 \\
methoxyphenyl triazine & 3.00 & 3.00 \\
Caprylic/capric triglyceride & 3.00 & 3.00 \\
Oleyl alcohol & 3.00 & 3.00 \\
Ethylhexyl stearate & 0.30 & 0.30 \\
Acrylates/C10-30 alkyl acrylate & & 0.20 \\
crosspolymer & 0.20 & 1.00 \\
Carbomer & 1.00 & 62.20 \\
Phenoxyethanol and caprylyl glycol & 52.20 & \\
Disttiled water & &
\end{tabular}

Table 2. O/W/O multiple emulsions compositions.

\begin{tabular}{lcc}
\hline \multicolumn{1}{c}{ Components } & $\begin{array}{c}\text { Formulation } 3 \\
(\mathrm{~F} 3)(\mathrm{g} \%)\end{array}$ & $\begin{array}{c}\text { Formulation } 4 \\
(\mathrm{~F} 4)(\mathrm{g} \%)\end{array}$ \\
\hline O/W Primary emulsion & 70.00 & 70.00 \\
BHT & 0.03 & 0.03 \\
Euterpe oleracea fruit oil & 3.00 & ---- \\
Octocrylene & 1.80 & 1.80 \\
2- Ethylexyl salicylate & 1.50 & 1.50 \\
2-Ethylhexyl 4- methoxycynnamate & 2.25 & 2.25 \\
Bis-Ethylhexyloxyphenol & 1.50 & 1.50 \\
methoxyphenyl triazine & 5.00 & 5.00 \\
Caprylic/ capric triglyceride & 5.00 & 5.00 \\
PEG-30 dipolyhydroxystearate & 5.00 & 5.00 \\
Sucrose polybehenate & 4.92 & 7.92 \\
Mineral oil & & \\
\hline
\end{tabular}

\section{Stability tests of multiple emulsions}

The samples did not show any changes in aspect and homogeneity when stored over a period of ninety days.

According to Nakhare \& Vyas (1996), this formulation showed no significant percent phase separation $(2.8 \%)$. Centrifugation can be used to predict the stability of the multiple emulsions (Özer et al., 2000) 
because the centrifugation accelerates the effects of gravity. When the freshly prepared and $24 \mathrm{~h}$ old multiple emulsions were centrifuged, no phase separation was detected.

There are different factors affecting the stability of multiple emulsions, including the concentration of the primary emulsion as well as the concentration and type of emulsifier.

The increase in the concentration of the primary emulsion increases the viscosity and decreases the droplet size. This effect can lead to the increase of stability (Baillet et al., 1994; Su et al., 2006). The O/W/O multiple emulsions were prepared with a $70 \%(\mathrm{w} / \mathrm{w})$ concentration of the primary emulsion.

The use of polymeric surfactants in multiple emulsions has been superior to monomeric emulsifiers because the monomeric types tend to migrate from the inner interface and from the outer interface and/or solubilize in one of the phases (Magdassi et al., 1985; Benichout et al., 2007; Vasiljevic et al., 2005; Vasiljevic et al., 2006). The results enable us to affirm that, for the preparation of physically stable multiple emulsions, a $5 \%(\mathrm{w} / \mathrm{w})$ concentration of polymeric surfactant was sufficient.

Based on Stokes' Law, by increasing the viscosity of the external phase, we can achieve improved emulsion stability (Klein, 2001). By adding 5\% (w/w) of sucrose polybehenate, we were able to increase the viscosity of the external phase of the multiple emulsions and improve the stability of the emulsion.

Rheological measurements of the formulations play an important role in the physical stability (Tadros, 1994; Rajinder, 2007; Rajinder, 2008). It is also essential to carry out rheological measurements as a function of temperature to obtain information on the stability and consistency of the formulations (Tadros, 2004).

The values of minimal apparent viscosities, flow index and hysteresis area values determined for formulations $24 \mathrm{~h}$ (first day) and ninety days after preparation at different temperatures are given in Table 3.

Table 3. Minimal apparent viscosity, flow index and hysteresis area values of $\mathrm{O} / \mathrm{W} / \mathrm{O}$ multiple emulsions (F3) during accelerated stability at different temperatures.

\begin{tabular}{ccccc}
\hline $\begin{array}{c}\text { Time } \\
(\text { days })\end{array}$ & $\begin{array}{c}\text { Temperature } \\
{ }^{\circ} \mathrm{C}\end{array}$ & $\begin{array}{c}\text { Minimal } \\
\text { apparent } \\
\text { viscosity }(\mathrm{cP})\end{array}$ & $\begin{array}{c}\text { Flow } \\
\text { index }\end{array}$ & $\begin{array}{c}\text { Hysteresis area } \\
\left(\mathrm{d} / \mathrm{cm}^{2} . \mathrm{s}\right)\end{array}$ \\
\hline 1 & 25 & $1606.0 \pm 144.1$ & $0.63 \pm 0.05$ & $21776.7 \pm 3909.9$ \\
& 4 & $1537.1 \pm 78.7$ & $0.61 \pm 0.01$ & $24199.3 \pm 2132.5$ \\
& 25 & $1587.5 \pm 89.0$ & $0.64 \pm 0.02$ & $26488.2 \pm 4302.4$ \\
90 & 37 & $1639.1 \pm 35.6$ & $0.63 \pm 0.01$ & $29610.0 \pm 1375.1$ \\
& 45 & $1711.9 \pm 106.1$ & $0.62 \pm 0.03$ & $23696.3 \pm 1896.3$ \\
\hline
\end{tabular}

Data were expressed as mean \pm S.D. $(\mathrm{n}=9) .{ }^{*} p<0.05$.
Constant apparent viscosities values during aging indicate good stability of this sample. It is known that the apparent viscosity and consistency index normally decreases or increases during storage, indicating instability (Tadros, 2004) however, in this case no was indicated because there was no significant decrease or increase observed in apparent viscosities when compared with the first day $(24 \mathrm{~h})$. However, the decrease of this index could be explained by the breaking of multiple droplets and/or the increase of the globules size (Tadros, 1994; Nakare \& Vyas, 1996). There were no significant differences in the apparent viscosity among the three batches formulated during the period and within the stress conditions investigated (Table 3).

The flow index (Table 3) was below 1.0 in all formulations indicating non-Newtonian pseudoplastic flow behavior, which is a desirable rheological property in these formulations (Guaratini et al., 2006). In this case, the viscosity decreases with the increase of the shear rate (Tadros, 2004). When the globules are aggregated, the reaction of the aggregates to shear can result in a shearthinning (pseudoplastic) flow. At low shear rates, the aggregates may be deformed but remain intact. As the shear rate is increased, the aggregates may be broken down to individual globules, decreasing friction and therefore viscosity (Yazan et al., 1995).

The rheograms (Figure 1) showed that the descending curve is below that of the ascending curve, indicating thixotropy in the systems (Tadros, 2004). Thixotropic behavior means a reduction in structural strength during the shear load phase, and the more or less rapid, but complete structural regeneration, during the subsequent rest phase (Tadros, 2004).

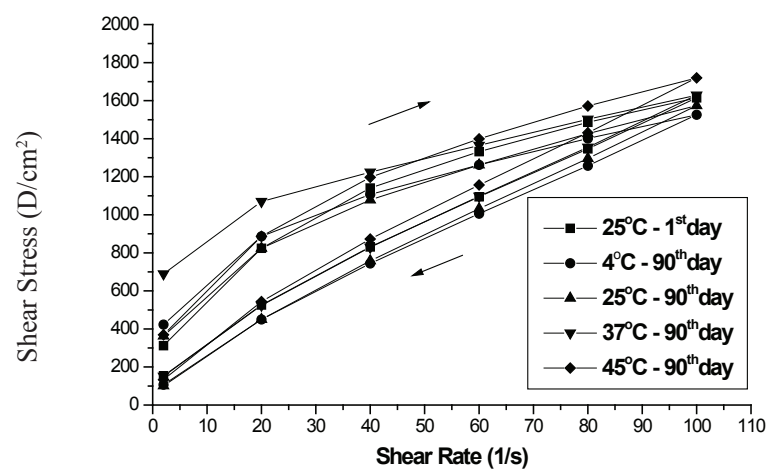

Figure 1. Flow behavior for a stable multiple emulsions $24 \mathrm{~h}$ and ninety days after preparation at different temperatures.

In vivo SPF determination

From the statistical analysis, it can be observed that the in vivo SPF values were not statistically significant different when both $\mathrm{O} / \mathrm{W} / \mathrm{O}$ multiple 
emulsions with or without açaí oil were compared (Table 4).

Table 4. In vivo sun protection factor (SPF) values determination of formulations.

\begin{tabular}{lcc}
\hline \multirow{2}{*}{ Formulations } & \multicolumn{2}{c}{ In vivo SPF } \\
\cline { 2 - 3 } & With açaí oil & Without açaí oil \\
\hline O/W/O multiple emulsions & $31.80 \pm 6.10$ & $33.00 \pm 4.40$ \\
CTFA/JCIA standard formulation & & $17.30 \pm 2.60$ \\
\hline
\end{tabular}

Data were expressed as mean \pm S.D. $(n=9)$.

The increase of the in vivo SPF value was not observed when açaí oil was incorporated into the emulsions containing sunscreens. In accordance with Acevedo et al. (2005) probably due to low concentration of the photoprotective compounds in the oil. This association did not show synergism because it did not lead to higher SPF values (Ramos et al., 1996; Souza et al., 2005; Ferrari et al., 2007; Ferrari et al., 2008).

These results support the hypothesis that the açaí oil does not have photoprotection activity.

\section{Conclusion}

The $\mathrm{O} / \mathrm{W} / \mathrm{O}$ multiple emulsions been found to be stables, but no difference could be observed in the in vivo SPF to both systems with and without açaí oil. These oil-in-water-in-oil multiple emulsions may find potential applications as a system to entrap sunscreens and an interesting vehicle for topical uses. The açaí oil cannot be used as a natural sunscreen because it does not absorb the UV radiation, and it does not increase the SPF value. However, it can be used in cosmetic products because of its antioxidant, anti-ageing and anti-inflammatory activities.

\section{Acknowledgments}

The authors thank Beraca Ingredients Co., Ciba Specialty Chemicals Inc., Croda of Brazil Ltda and ISP Corp. for the gift of sample materials, Allergisa for carrying out the in vivo SPF measurements. This work was supported by UNIC and by grants from Fundação de Amparo a Pesquisa do Estado de Mato Grosso.

\section{References}

Acevedo JGA, Castañeda CMC, Benitez FJC, Durán DA, Barroso VR, Martinez CG, Muñoz LJL, Martínez CA, Vivar AR 2005. Photoprotective activity of Buddleja scordioides. Fitoterapia 76: 301-309.

Baillet A, Pirishi E, Vaution C, Grossiord J-L, Ferrier-Baylocq D, Seiller M 1994. Emulsion multiple de type L/H/L: étude de l'obtention et du mécanisme de libération. Int $J$ Cosmet Sci 16: 1-15.

Becher P 1965. Emulsions: theory and practices. New York:
Reinhold.

Benichout A, Arserin A, Garti N 2007. O/W/O double emulsions stabilized with WPI-polysaccharide complexes. Colloid Surface A 294: 20-32.

Bonnet M, Cansell M, Berkaoui A, Ropers MH, Anton M, Leal-Calderon F 2009. Release rate profiles of magnesium from multiple $\mathrm{W} / \mathrm{O} / \mathrm{W}$ emulsions. Food Hydrocolloid 23: 92-101.

Colipa, CTFA SA, JCIA, CTFA 2006. International Sun Protection Factor Test Method. http://www.colipa. eu/publications/guidelines.html?view=item\&id=21, access in January 2010.

Córdova-Fraga T, Araujo DB, Snachez TA, Elias Junior J, Carneiro AAO, Brandt-Oliveira R, Sosa M, Baffa O 2004. Euterpe oleracea (Açaí) as an alternative oral contrast agent in MRI of the gastrointestinal system: preliminary results. Magn Reson Imaging 22: 389393.

ElShafei GMS, El- Said MM, Attia HAE, Mohammed TGM 2010. Environmentally friendly pesticides: essencial oil-bases w/o/w/ multiple emulsions for anti-fungal formulations. Ind Crop Prod 31: 99-106.

Erös I, Balázs J, Péter I, Tacsi M 1990. Investigation of drugcontaining multiple phase emulsions. Pharmazie 45: 419-422.

Ferrari M, Maruno M, Nakano AK, Rocha Filho PA 2008. In vivo evaluation of the photoprotective efficacy of $\mathrm{O}_{1} / \mathrm{W} / \mathrm{O}_{2}$ with Andiroba Oil (Carapa guianensis). $J$ Disp Science and Technol 29: 1203-1208.

Ferrari M, Oliveira MSC, Nakano AK, Rocha Filho PA 2007. Determinação do fator de proteção solar (FPS) in vitro e in vivo de emulsões com óleo de andiroba (Carapa guianensis). Rev Bras Farmacogn 17: 626-630.

Florence AT, Whitehill D 1981. Some features of breakdown in water-in-oil-in-water multiple emulsion. $J$ Colloid Interface Sci 79: 243-256.

Florence AT, Whitehill D 1982. The formulation and stability of multiple emulsions. Int J Pharm 11: 277-308.

Gallardo V, Hernández A, Parera A, Ruiz MA 1999. The effect of preparation technique on droplet size in silicone emulsions. J Cosmet Sci 50: 9-14.

Gallori S, Bilia AR, Bergonzi MC, Barbosa WLR, Vincieri FF 2004. Polyphenolic constituents of fruit of Euterpe oleraceae Mart. (açai palm). Chromatographia 59: 739-743.

Geiger S, Tokgoz S, Fructus A, Jager-Lezer N, Seiller M, Lacombe C, Grossiord J-L 1998. Kinetics of swellingbreakdown of a w/o/w multiple emulsion: possible mechanisms for the lipophilic surfactant effect. $J$ Control Release 52: 99-107.

Ghazi S, Couteau C, Coiffard LJM 2010. What level of protection can be obtained using sun protective clothing? Determining effectiveness using an in vitro method. Int J Pharm 397: 144-146.

Guaratini T, Gianeti MD, Maia Campos PMBG 2006. Stability of cosmetic formulations containing esters of Vitamins E and A: chemical and physical aspects. Int J Pharm 327: 12-16.

Kang J, Li Z, Wu T, Jensen GS, Schauss AG, Wu X 2010. Anti- oxidant capacities of flavonoid compounds isolated from açai pulp (Euterpe oleracea Mart.). 
Food Chem 122: 610-617.

Katiyar SK, Elmets CA 2001. Green tea and skin photoprotection. Cosmet Toiletries 116: 69-76.

Klein K 2001. Understanding factors that influence emulsion instability: Stokes'law. Cosmet Toiletries 116: 20-22.

Kullavanijaya P, Lim H 2005. Photoprotection. J Am Acad Dermatol 52: 937-958.

Lichtenthãler R, Belandrino R, Maia JGS, Papagiannopoulos M, Fabricius H, Marx F 2005. Total oxidant scavenging capacities of Euterpe oleracea Mart. (Açai) fruits. Int $J$ Food Sci Nutr 56: 53-64.

Lima CG, Pianovski AR, Vilela AFG, Silva KK, Carvalho VFM, De Musis CR, Machado SRP, Ferrari M 2010. $\mathrm{O} / \mathrm{W} / \mathrm{O}$ Multiple emulsions containing Amazon oil: Babassu Oil (Orbignya oleifera). J Disper Sci Technol 31: 622-626.

Lima CG, Vilela AFG, Pianovski AR, Silva KK, Carvalho VFM, De Musis CR, Machado SRP, Ferrari M 2008. Desenvolvimento e avaliação da estabilidade física de emulsões O/A contendo óleo de babaçu (Orbignya oleifera). Rev Bras Farmacogn 89: 239-245.

Magdassi S, Frenkel N, Garti N 1985. Correlation between nature of emulsifier and multiple emulsion stability. Drug Dev Ind Pharm 11: 791-798.

Matheus ME, Fernandes SBO, Silveira CS, Rodrigues VP, Menezes FS, Fernandes PD 2006. Inhibitory effects of Euterpe oleracea Mart. on nitric oxide production and iNOS expression. J Ethnopharmacol 107: 291-296.

Moquio A, Rivera-Megret F, Daja F 2005. Photoprotection by topical application of Achyrocline satureioides (Marcela). Phythother Res 6: 486-490.

Muñiz-Miret N, Vamos R, Hiraoka M, Montagnini F, Mendelsohn RO 1996. The economic value of managing the açai palm (Euterpe oleracea I Mart.) in the floodplains of the Amazon estuary, Pará, Brazil. Forest Ecol Manag 87: 163-173.

Nakhare S, Vyas P 1996. Preparation and characterization of multiple emulsion based systems for controlled diclofenac sodium release. J Microencapsul 13: 281292.

Omotosho JA 1990. The effect of acacia, gelatinand polyvinylpyrrolidona on chloroquine transport from multiple w/o/w emulsions. Int J Pharm 62: 81-84.

Özer Ö, Baloglu E, Ertan G, Muguet V, Yazan Y 2000. The effect the type and the concentration of the lipophilic surfactant on the stability and release kinetics of the w/o/w multiple emulsions. Int J Cosmet Sci 22: 459470.

Pacheco-Palencia LA, Duncan CE, Talcott ST 2009. Phytochemical composition and thermal stability of two commercial açaí species, Euterpe oleracea and Euterpe precatoria. Food chem 115: 1199-1205.

Pacheco-Palencia LA, Hawken P, Talcott ST 2007. Phytochemical, antioxidant and pigment stability of açai (Euterpe oleracea Mart.) as affected by clarification, ascorbic acid fortification and storage. Food Res Int 40: 620-628.

Rajinder P 2007. Rheology of double emulsions. J Colloid Interface Sci 307: 509-515.

Rajinder P 2008. Viscosity models for multiple emulsions. Food Hydrocolloid 22: 428-438.
Ramos MRS, Santos EP, Bizarri CHB, Mattos HA, Padilha MRS, Duarte HM 1996. Preliminary studies towards utilization of various plant extracts as antisolar agents. Int J Cosmet Sci 18: 87-101.

Ribeiro CR, Antunes LMG, Aissa AF, Darin JDC, De Rosso VV, Mercadante AZ, Bianchi MLP 2010. Evaluation of the genotoxic and antigenotoxic effects after acute and subacute treatments with açai pulp (Euterpe oleracea Mart.) on mice using the erythrocytes micronucleus test and the comet assay. Mutat Res 695: 22-28.

Rocha APM, Carvalho LCRM, Sousa MAV, Madeira SVF, Sousa PJC, Tano T, Schini-Kerth VB, Resende AC, Soares De Moura R 2007. Endothelium-dependent vasodilatador effect of Euterpe oleracea Mart. (Açaí) extracts in mesenteric vascular bed of the rat. Vasc Pharmacol 46: 97-104.

Schauder S, Ippen H 1997. Contact and photocontact sensitivity to sunscreens. Contact Dermatitis 37: 221232.

Schmidts T, Dobler D, Nissing C, Runkel F 2009. Influence of hydrophilic surfactants on the properties of multiple w/o/w emulsions. J Colloid Interface Sci 338: 184192.

Souza TM, Santos LE, Moreira RRD, Rangel VLBI 2005. Avaliação da atividade fotoprotetora de Achillea millefolium L. Rev Bras Farmacogn 15: 36-38.

Su J, Flanagan J, Hemar Y, Singh H 2006. Synergistic effects of polyglycerol ester of polyricinoleic acid and sodium caseinate on the stabilization of water-oilwater emulsions. Food Hydrocolloid 20: 261-268.

Tadros T 2004. Application of rheology for assessment and prediction of the long-tern physical stability of emulsions. Adv Colloid Interface Sci 108/109: 227258.

Tadros THF 1994. Fundamental principles of emulsion rheology and their applications. Colloid Surface A 91: 39-55.

Tedajo GM, Bouttier S, Fourniat J, Grossiord J.-L, Marty JP, Seiller M 2005. Realease of antiseptics from the aqueous compartments of a w/o/w multiple emulsion. Int J Pharm 288: 63-72.

Tonon RV, Bradet C, Hubinger MD 2010. Anthocyanin stability and antioxidant activity of spray-dried açai (Euterpe oleracea Mart.) juice produced with different carrier agents. Food Res Int 43: 907-914.

Van der Pols JC, Willians GM, Neale RE, Clavarino A, Green AC 2006. Long-term increase in sunscreen use in an Australian community after a skin cancer prevention trial. Prev Med 42: 171-176.

Vasiljevic D, Parojcic J, Primorac M, Vuleta G 2006. An investigation into the characteristics and drug release properties of multiple $\mathrm{W} / \mathrm{O} / \mathrm{W}$ emulsion systems containing low concentration of lipophilic polymeric emulsifier. Int J Pharm 309: 171-177.

Vasiljevic, D., Vuleta, G., Primorac, M 2005. The characterization of the semi-solid $\mathrm{W} / \mathrm{O} / \mathrm{W}$ emulsions with low concentrations of the primary polymeric emulsifer. Int J Cosmet Sci 27: 81-87.

Velasco MVR, Sarruf FD, Salgado-Santos IMN, Haroutiounian-Filho CA, Kaneko TM, Baby AR 2008. Broad spectrum bioactive sunscreens. Int $J$ 
Pharm 363: 50-57.

Violante IMP, Souza IM, Venturini CL, Ramalho AFS, Santos RAN, Ferrari M. 2008. Estudo preliminar da atividade fotoprotetora in vitro de extratos vegetais do cerrado de Mato Grosso. Rev Bras Farm 89: 175-179.

Violante IMP, Souza IM, Venturini CL, Ramalho AFS, Santos RAN, Ferrari M 2009. Avaliação in vitro da atividade fotoprotetora de extratos vegetais do cerrado de Mato Grosso. Rev Bras Farmacogn 19: 452-457.

Yazan Y, Seiller M, Grossiord J-L 1995. PVP in multiple emulsions. Cosmet Toiletries 9: 53-57.

Yoshida K, Sekine T, Matsuzaki F, Yanaki T, Yamaguchi M 1999. Stability of vitamin A in oil-in-water-in-oiltype multiple emulsions. J Am Oil Chem Soc 76: 195 -
200.

Zhang K-M, Yu H-J, Shi K, Zhou Y-H, Yu J-Q, Xia -J 2010. Photoprotective roles of anthocyanins in Bergonia semperflorens. Plant Sci 179: 202-208.

\section{*Correspondence}

Márcio Ferrari

Universidade Federal do Rio Grande do Norte

Rua Gustavo Cordeiro de Farias, s/n. Petrópolis. 59012-570 Natal-RN, Brazil

ferrarimarcio@ufrnet.br

Tel.: +55 8433429812

Fax: +55 8432084798 